Ioana SCHIAU*

Loredana IVAN**

Monica BîRA $\breve{A * *}^{* * *}$

\title{
Involving Older People in Participatory Action Research: An Example of Participatory Action Design
}

\begin{abstract}
Participatory Action Research (PAR) has as a main goal the collaborative construction and production of meanings between the researchers and the participants. PAR has been largely used in the area of technology creation and appropriation involving end-users in different stages of technology designing process. However, research studies concerning older people and their use of technology employ PAR to a lesser extent. In the current paper we provide arguments for the value of different participative action approaches when studying technology appropriation by older people, and present an example of a participatory action design that we have implemented in three Romanian cities, with people $60+$, to reveal the way older adults depict their experience in using Facebook. We used a five-step collaborative research design - (1) initial evaluation; (2) training session; (3) immediate evaluation; (4) group co-creation; (5) final evaluation - to reflect on the participants' experience through groups techniques and participant observation notes. Results reveal the fact that one trainer per each participant, adapting the interaction to the participant's individual needs, intergenerational trainer-trainee communication and patience, as well as proper timing of the organized sessions are key factors to foster participant engagement with social media. In addition, the proposed participatory action design proved to have some potential to empower older people in long time engagement with social media.
\end{abstract}

Keywords: Participatory Action Research (PAR), PAR \& older people, Participatory Action Design (PAR), older people and social media engagement.

\section{Introduction}

During the last decades, research rhetoric has moved to not only include multidisciplinary, interdisciplinary, and transdisciplinary approaches, but also an action-oriented approach that challenges the traditional relationship between the subject, the object and the context of

${ }^{*}$ National University of Political Studies and Public Administration (SNSPA), Romania ioana.schiau@comunicare.ro.

** National University of Political Studies and Public Administration (SNSPA), Romania loredana.ivan@comunicare.ro.

${ }^{* * *}$ National University of Political Studies and Public Administration (SNSPA), Romania monica.bira@comunicare.ro. 
the research. The increasing interest in participatory action research (PAR) sought to reconnect the ivory tower of academic research with a more hands-on approach of social dynamics (Chevalier \& Buckles, 2013, p.1). Aimed to empower "ordinary people" in and through research (Kindon, Pain, \& Kesby, 2007), this bottom-up approach has gained centrality not only in social science, but also in health or environmental sciences, as it provides a powerful interplay between research and practice.

The core research dynamic is the collaborative construction and production of meanings between the researchers and the participants. Therefore, the relationship between the researcher and the subjects of the research is redefined in less hierarchical terms, as it is no longer about the symbolic dominance and control of the former over the research process. On the contrary, PAR is primarily about a dialogic framework in which the participant takes on an active co-researcher role and is, hence, actively engaged in the research process at all stages. From a broader sociological theoretical perspective, this could place PAR within a symbolic interactionism logic (Genat, 2009), as meanings and interpretations emerge and are subject to a continuous process of negotiation between the researchers and the participants, as well as between the participants themselves. One of the main advantages of facilitating a collaborative research context is that "the practical knowledge that emerges is usually a better fit for those for whom it is intended, since they themselves helped generate and make sense of the findings" (Piercy et al., 2011, p.821).

\section{Participatory Action Research in the Area of Technology Creation and Appropriation}

PAR is significant in the area of ICT with the implementation of user-friendly design of applications to fit customers' needs and daily habits. Such approaches are employed by the field of Human-Computer-Interaction (HCI) and are used for prototype designing and testing, concerning the final product/application appropriation and use. Therefore, the approach is defined as Participatory Action Design (PAD), as a model of involving users in the cocreation of the designing product, alongside the entire process (Ding, Cooper, \& Pearlman 2007). The Research and Development (R\&D) areas are using PAD by involving end-users in different stages of the process: establishing a research agenda, formulating the research questions, involving participants as research assistants or advisors, involving participants in testing prototypes or ideas and in the evaluation process - as for example continuation in use, advantages and dis-advantages of the implemented ideas (Wu, Richards, \& Baecker, 2004). Since the first uses of PAD models in the 1970s, when they assisted the implementation of computers in work environments, the approach has been successfully extended to other areas, such as urban design and transportation (see Carmona, 2010; Taylor, Braveman, \& Hammel, 2004). Still, PAD remains a research approach largely used in the ICT design for users with reduced capabilities or impairment associated with ageing: for example mobility related problems (Hitchen, Williamson, \& Watkins, 2015; Muller, 2003; Seale et al. 2002) and Ambient Assistant Living (AAL) technologies designing or socio-technical solution (i.e. Quality of Life technology- QoLT devices and systems) to reduce the effects of cognitive impairment or other cognitive disabilities impacting individuals' social life (Slegers et al., 2012; Spinuzzi, 2005). The use of PAD model in research follows some steps in which the end-users get involved in the co-creation process (see for example Ding, Cooper, \& Pearlman, 2007): (1) 
identification of the users' needs, mainly through semi-structure interviews, focus groups, brainstorming or similar open discussions, some using participants as moderators or facilitators; (2) getting all the information together to design the possible solutions of prototypes features; (3) testing prototypes/ideas and determining perceived advantages and disadvantage of each. This will include feedback questionnaires, interviews and observation; (3) designing the final product in accordance with industry standards and available benchmarks. This will be the final prototype which has to be feasible; (4) evaluation of the results with the coparticipation of the potential users: testing for the durability, availability, easiness to use and appropriation. Here observation, small experimental designs and in-depth interviews are usually revealing for the consumers' desire to use that particular product, the relevance for daily routine or specific needs and meanings associated with the prototype appropriation or rejection; (5) Adjustments of the prototype could be done as a result of the evaluation process and different ways to present the product/idea on the market constructed, with the involvement of the end-users as well. Note that participants could be involved in all five steps of PAD to different degrees, from coordinating the data themselves and analyzing it, to testing and discussing the products elaborated by the researchers.

\section{Photo Voice}

PhotoVoice is a participatory action research technique mostly used in the process of identifying community problems, describing them "from the inside", using visual representations and discussions of the associated meanings, while empowering the community through the entire process (Flicker et al., 2008). The photographic techniques are used and participants are trained to portray their communities, by the means of basic photographic and reflective skills. Photo Voice technique enables communities and prepares policy plans by starting from "the real" community problems and the subjective meanings people invest in revealing the community problems (Wan, 1999). This strategy involves three steps: (1) participants are trained to record and reflect on their own community issues, including strengths and weaknesses. The use of photographic techniques is required at this stage, when employing Photo Voice as a PAR strategy; (2) participants are encouraged to discuss the data (the collected photos) using groups techniques, to share knowledge and the meanings of different community issues, as they appeared in the photos, and to describe their own experience in facing those community problems; (3) researchers aim to reach policy makers using the data obtained in the previous steps. An in-depth analysis on both the photos recorded by participants and the discussed meanings of the community problems creates the bases for the research report and for future policy implementation. Planners brought to table are used as an audience for the community people's perspective. Finally, Photo Voice is about community and individual's empowerment (Hergenrather et al., 2009).

\section{Ethnographic Action Research}

A particular type of Participatory Action Research is Ethnographic Action Research (EAR). Although both PAR and EAR use ethnographic research tools (interviews, observation, participant observation and field notes), EAR involves an ethnographic approach in data collec- 
tion as well (Tacchi, Foth, \& Hearn, 2009). For example, when using EAR to research media practices, the capacities of different media to record, select and present the data are used as such, with the researcher playing an active role: not only monitoring and evaluating the media practices for the researched social group, but also altering those practices from inside (as a member of the social group). The level of involvement for the researcher in changing media practices is different from a research study to another, while performing different types of "interventions". As Tacchi, Foth, \& Hearn (2009, p. 31) stated, EAR employs a "communicative ecology" meaning that it is a reflective way of doing participatory action research: we reflect both on interventions and their functional roles in the media practices, for example, but also on the effects generated by each type of intervention. For example, in a study on the way older individuals learn to interact using a new communication technology tool, we might reflect on different ways to introduce this particular tool, as well as on the obstacles and advantages people experience (observational notes) or perceive (in-depth interviews) during the appropriation sessions. Here the ethnographic approach is broadly used, not only at a methodological level, but for the entire research process. Another particularity of EAR is the fact that "the research object" is treated in the same time as the "subject" of the research. For example, when examining media practices of different social groups - the research subject, we can use media tools to collect, archive and groups the data in categories the research object. Even more, the power relationships between researchers and participants are flexible, permanently shifting and changing (Rodriguez, 2001) in a co-creation process in which both parts (researchers and participants) have their role in creating and analyzing data. The final goal is "communication for social change", as EAR addresses the gap between research and intervention (Tacchi, Foth, \& Hearn, 2009, p. 32). Learning "from the inside" and grounded forms of participation consist of mixing knowledge and reflection (Hickey \& Mohan 2004), with participants taking the researcher's role or the role of a trainer, an advisor in planning and acting when findings occur. The grounded theory approach (Glasser, 1998 ) is the fundament for the EAR with "thick descriptions" and bottom-up approach.

\section{Involving Older People in Participatory Action Research}

It is important in the investigation of ICT practices for older adults, to take into account the fact that their needs in using different types of technologies might be different compared to other age groups. Previous studies (Fernández-Ardèvol \& Ivan, 2013) revealed the fact that older people have a utilitarian approach in their decision to appropriate a particular device or technology, whereas younger users base their decision more on self-satisfaction that could even be described as hedonistic. Older adults might start to use a particular device because they perceive certain functional value for everyday interactions, whereas adolescents might choose a particular device or application because "it is cool to do it", or to gain acceptance from peer groups. Therefore participatory action research could be employed as a methodological option to research media practices by focusing on older people's needs (Demiris et al., 2008). The design and training for different technology applications, including social network applications, would benefit from the co-creation data by empowering older people and making them more active participants. We agree with Fudge, Wolfe, \& McKevitt (2007, p. 492) that benefits for using PAR with old participants could be "increasing their knowledge, awareness and confidence, meeting others in similar situations, empowering old people to 
become active members in their communities regarding decisions/policies which affect them". The same is valid for research concerning older people and media practices. As previously proved (Fernández-Ardèvol \& Ivan, 2015), age is not a barrier in itself, but a mediator for people's familiarity to ICTs and their self-confidence in approaching new applications. Participant Action Research could be a methodological approach to address both issues: (1) In terms of familiarity, the direct experience in using a type of technology/application while having the opportunities to reflect on the experience could have a positive effect; (2) In terms of self-confidence, the experience of producing and critically analyzing data could enhance positive meaning associated with a particular type of technology.

Also, in previous research on older people and the use of Facebook (Ivan \& Hebblethwaite, 2016) we revealed the fact that the use of photos to document their everyday life could be an important aspect of the media practices for this age group, even though the skills in creating visual content are, generally speaking, lower than for younger adults. Consequently the use of Photo Voice technique might hold the potential in the studies conducted using PAR with older participants. Still, few research studies have used PAR to assess media practices of older adults and no study that we know about employed PAR to research the way older people are using social and interaction applications (e.g. Facebook, WhatsApp).

\section{Older People and Social Media}

Recently, the way older people interact with technology and social media has been explored both from the point of view of practical issues such as adopting digital and mobile technology or acquiring and setting up technology and devices (Burrows, Mitchell, \& Nicolle, 2016; Campanella Bracken, Yang \& Pettey, 2015) but also from a broader perspective, focused on the role and meaning of social media into the life of older people.

Although the tendency was to explore how older people are using social media as opposed to younger audiences, and thus to reduce people to age groups - recent studies are unveiling and addressing all sorts of 'blind spots' when it comes to research on this specific topic, such as: (1) generational and intergenerational issues and (2) diversity and digital inequalities. Intergenerational projects (Randal, 2012) and intergenerational communication (Tamme \& Siibak, 2012) are privileged by research focused on the role of social media in increasing social and family cohesion, being usually placed in contexts related to significant social changes (see also Ivan \& Hebblewait, 2016). Generational issues are outlined by ethnographic approaches and investigations into how social media practices play an important role in generational identity building or re-configuration (Napoli, 2014) but also in connection with social wellbeing of older adults (Ihm \& Hsieh, 2015). Recent studies point out that diversity, inequality and variations related to the lived experiences are more important than the age itself (Givskov \& Deuze, 2016) and therefore it might be useful to adopt a 'cultural conception' of media generations, according to which neither the development of media technologies nor people's ages are relevant in themselves (Kalmus et al. 2013). 


\section{Our Participatory Research Design}

Following the literature review, we designed a research study to reveal the way older people depict their experience with Facebook as an interaction tool using Participatory Action Research. The findings presented in this paper address the way the participants perceived and discussed the advantages and disadvantages of the PAR design. Findings pertaining to the participants' experience of appropriating the new technology will be discussed in a followup paper. Consequently, we proposed the following research questions for the current study:

RQ1: What are the perceived factors that contributed to the efficiency of the PAR design implementation?

RQ2: What were the participants' main motivations to engage in a social media participatory action research?

RQ3: How do the participants perceive the effectiveness of the PAR design in terms of creating long-term empowerment to use social media?

\section{Participants}

The design was applied during February-June 2016 in a series of three research studies, conducted in three Romanian cities (Bucharest, Brașov and Bacău), with 10-12 participants aged 60+ for every training session, as follows: 12 participants in Bucharest, 11 in Braşov and 10 in Bacău. In all locations, the participants were recruited using a convenience sampling procedure, and covered a variety of older age groups (60-85) and socio-demographic categories relevant to the study.

\section{Procedure}

The emphasis was placed on the ethnographic approach, using groups' techniques and participant observation notes. The research procedure involved five steps, as follows:

Step1. Initial evaluation. A semi-structured group interview was conducted with 10 to 12 participants, 60 years and older, that subsequently took part in a training session about the use of Facebook in everyday interactions. Here the aim was to assess the initial level of participants' knowledge, familiarity, and interest to use this application, as well as motivation, incentives to use social networks, perceived advantages and disadvantages.

Step2. The training session. We used students as trainers to assist participants in improving their skills in using Facebook. One trainer was assigned to each participant and worked together according to his/her own level of knowledge, familiarity, and motivation. Participants were assisted in creating their own Facebook profile, or/and creating content changes for a previously existing Facebook profile, or in personalizing their profile. Here open discussion was employed by the trainer to identify participant interests, type of communication when using social network sites and the network structure, preferred topics of discussion and online content creation, concerns issues such as privacy and decency. We used observational notes during the interaction between trainers and trainees and recorded materials from the training sessions to be used in further analysis. 
Step3. Intermediate evaluation. Group discussion in which participants shared their experience during the training session, the meanings they associate with the process and the type of "social media outcomes"/ user generated content they created. Participants discussed the difficulties, opportunities they perceived during the training process, and their intention regarding the use of Facebook after the session.

Step4. Facebook group co-creation. Participants discussed and created a Facebook group to be used by themselves in further interactions. The structure, type of group, layout, and other personalized details are constructed in interaction, trainers having a supportive role. $\mathrm{Ob}-$ servational notes and video materials will record the process. Inspired by the Photo Voice strategy, each participant was asked to take a photo that represents the experience of working together and to post it on the group. They also had the possibility to reflect on the choice then made - the photo they have selected and its meaning.

Step5. Final evaluation. Individual semi-structured interviews were conducted with each of the participants. Details about the subjective meaning of each of the previous steps and the overall assessment of the methodologic design will be critically discussed. Limits of this research design, as well as opportunities would be critically discussed in this stage. The intention of each participant to continue to use communication via Facebook through his/her own profile and group profile will be assessed and the participants' estimation about their future involvement and empowerment in using social networks will be recorded. For the next three months, we further objectively measured their level of involvement on their Facebook profiles and group profile.

\section{Results}

\section{The Participants' Perception of the Participatory Action Design}

In the final evaluation stage (stage 5), interviews were conducted with the study participants in all three locations where the participatory action research design was carried out, in order to reflect on the experience and identify perceived advantages and disadvantages of the applied methodology. We present here part of the study findings that pertain to the participants' reflections on the PAR design and provide an answer to RQ1: What are the perceived factors that contributed to the efficiency of the PAR design implementation?

\section{Belonging - Building Rapport and the Impact of the Initial Evaluation}

Participants reflected on the importance of building a connection between the trainer and the trainee and the effect of a positive learning environment for ICT skills acquisition. The initial evaluation (semi-structured group interview) was perceived as relevant in order to create a sense of communion and to create self-confidence.

"I liked the atmosphere, how you organized the meeting at the beginning, the circle where people could get to know each other. I can say that we knew each other but we also got to know you. It was like, the fact that you didn't just sit us at our desks and say 'You go there, you go there...', we were feeling like first graders, we were nervous, we are of a certain age but it still felt intimidating, but it was wonderful, the idea of that circle which united us and made us trust each other, it was important". (Woman, 66, Braşov) 
"It was good and everyone was like in a big family, we interacted very well and that is very important. It gives you a lot of confidence." (Woman, 63, Bucharest)

Participants indicated an increased level of self-confidence by comparing the workshop experience with a family, or by using such expressions as "a circle that united us". It could be suggested that a sense of belonging was built and that it is this feeling that facilitated not only the interaction between trainer and trainee, but also the interaction with technology.

\section{The importance of asking questions: One Trainer for Each Participant}

Participants reflected on the advantage of having an individual trainer. Their expectations had been that the session would be conducted in a lecture style, with one instructor in the front of the class and each participant working, individually and unassisted, on a personal computer. The possibility of benefiting from a personal trainer was seen as an important advantage to aid ICT skill acquisition. The interaction was described as friendly, almost like a conversation with "an older brother", pointing to shifting power dynamics between the participant and the researchers, specific to EAR. A design that would have only included one trainer for the entire group was perceived as not allowing the opportunity for all those involved to ask questions and gain the precise information they need.

"I was used to university, I thought there would be one person teaching the course and that I would
have to follow, that maybe they would write on a blackboard. And that maybe we could ask some
questions. It was much better organized than that, like a private tutoring, which was more efficient".
(Man, 71, Bucharest)
"The gain is that if there are more [participants] you do not manage to deepen your understanding
of what you are doing, like we did, one person to another, you can ask questions. If there was only
one person [trainer] and something general you would have left [the workshop] unclarified; for sure".
(Woman, 67, Bucharest)

The mere fact of being able to ask specific questions seemed to improve the perceived quality of interaction and exchange during the course. Participants associated this feature with an added value related to efficiency.

"I think teaching one on one is the best method. In an official environment there are all sorts of people, some are shier, some have more courage, and the shy ones do not have the courage to ask things, either because they do not want to be seen as unprepared, or because they are embarrassed, but a conversation between two people is friendlier, like a conversation with an older brother. Even if the result might have been similar [in a format with just one instructor], this method is more efficient". (Man, 64, Bacău)

"I thought we would each have a computer and that there would be a trainer for all. That's what I thought but it was very good that they could take care of us more closely. (Woman, 69, Braşov)

"Something that was perfect was, like when you learn to drive, I mean the dual control. Otherwise it would have meant you being on my computer and I would not have learned anything. People learn best when they can observe what another person is doing and if you don't understand you can ask and repeat and so on, like I did". (Man, 71, Bucharest)

The expressions used by participants in order to describe the way in which the workshop was organized (e.g. "private tutoring", "one to one", "dual control", "more closely") convey the idea of a balance or a lack of disparity between the trainer and the trainees. Participants associated this feature with efficiency, but further research into the matter might point out other ways of creating self-confidence and a feeling of empowerment. 


\section{Adapting to the Participant's Individual Needs}

Participants indicated that the training session was perceived as efficient because the information was adapted to individual needs.

"It's important to... to... to build a relationship between the trainer and the trainee... You know, to see what his level is, what he wants to get from the course, what he would like to have clarified and, I don't know, their character. To see how you can best get to the person." (Woman, 63, Bucharest)

"I mean it was complex... I thought it's something... that we can ask some questions and get the answers and that's that, but it was really... the fact that it was focused on practice was very important to me". (Woman, 64, Bucharest)

"I liked that any question you asked, no matter how stupid or simple, was answered and they didn't leave your side. Afterwards they asked you to do it on your own, with assistance but to manage what you had set out to do". (Woman, 84, Brașov)

Adapting to the participant's need was considered to be a significant mark of efficiency ensuring opportunities to clarify and ask questions. Participants related this to the relationship with the trainer, companionship during the activities ("they didn't leave your side") and assistance. It is for this reason that we might consider that the perceived efficiency is not only a matter of being able to address practical questions (how to do this or that) but, first and foremost, a matter of being listened to.

\section{Intergenerational Trainer-Trainee Communication and the Issue of Patience}

Participants in the study reflected on the nature of their interaction with the trainers, which were described as "patient youth" (Woman, 67, Braşov). This description is in contrast with many of the participants' perceptions of their own family members, which were, in the initial evaluation, described as lacking patience to assist with ICT use, when assistance was needed: "I don't know at all [how to use modern ICT], only my children and grandchildren do. But they don't have the patience to teach us" (Man, 68, Braşov); "We were patient with our children and grandchildren, but they are not patient with their grandparents" (Woman, 70, Braşov). Thus, there is evidence that the use of students and early career investigators as trainers, in an inter-generational design, could contribute to reduce the perceived tension between generations, in relation to ICT use.

"I liked everything, the atmosphere, the way of communicating and the fact that you were so close to the group and there were big age differences but you never let these differences show." (Woman, 66, Brașov)

"The fact that you were patient with us, you did not react when we maybe seemed illiterate or how should I call it." (Woman, 68, Braşov)

"Young people are right for this, because they are patient. They are not bored and I think they are very... if a person is bored for years and years I don't think it can come out so well. I think they are polite and they know the technology very well and are used to this computer technology (...)". (Woman, 64, Bucharest)

"I suppose one can work better with someone your age, you are just starting off, your motivation to share your experience is high. I don't mean to say that an older person... it could be... but I think 
an older person has lost the necessary patience, and the motivation is not the same anymore, is it?" (Woman, 63, Bacău)

The fact that participants seemed to associate youth with patience is a feature that needs closer investigation. The fact that, in this specific learning environment, the older adults overlooked the stereotypical view of young people as impatient and always in a hurry provides an insight into the potential of participatory action research to influence perceptions.

\section{Subjective perception of time: The Training Session and the Issue of Time}

Several participants reflected on their perception of time during the training session, stating that time really flew by very quickly, because the activity was perceived as enjoyable; at the same time, when discussing ways to improve the design of the training session, participants indicated the need for longer and more frequent meetings.

"First of all, I didn't even feel the time go by, which is proof that it was interesting. The conversations were on point, we also went off-topic, and it was something relaxing. If you only focus on one subject, you get tired, but when you change the subject a little bit you don't tire yourself out intellectually." (Man, 71, Bucharest)

"The team was very pleasant and everything went so smoothly that I didn't even look at my watch to see time go by, on the contrary, I could not believe it had turned 14.00 or later, it was all so... I really didn't feel the time go by because I was so concentrated on what A. [trainer] was saying". (Woman, 67, Braşov)

Several participants felt that the design could be improved simply by extending the duration of the training session: "About two consecutive weeks. It would be enough even if we went from illiteracy, because there are certain terms in computer language and you need to know them. That's what I think would be better, smaller groups over a longer period". (Woman, 71, Braşov)

"To be honest, I expected it to last longer, having in mind that some of the participants are at stage zero, and it will take them a while to memorize". (Man, 71, Bucharest)

It follows that subjective perception over the duration of the training sessions could be reduced to two main issues. Firstly, the feeling of 'time flying' referred to by participants was linked to the engaging nature of the activity. Secondly, participants considered that repeated and intensive training might have increased the overall efficiency of the training sessions. Those two conclusions seem rather obvious: all educators are aware that in order to succeed in their teaching activities, those activities must appear as interesting, and entertaining in the eyes of their pupils. In this instance, the participants reported their deep involvement in the activites and how easily the time passed.

\section{Participants' Reflections about Social Media Engagement}

Consistent with the findings of Fernández-Ardèvol, \& Ivan (2013), older people in the study groups described a utilitarian approach in their decision to appropriate the new technology, based on a perceived advantage or utility of using said ICT. We highlight some of the find- 
ings that answer RQ2 and reflect the participants' motivations for engaging in a training session to learn the use of a social media platform.

\section{Diverse Motivations to Engage on Facebook}

Reasons for participating in the study and the training sessions were diverse, ranging from the desire to communicate swiftly and keep in touch with friends and family who live far away, to the ability to express opinions in an online agora and to participate in public debates. The ability to send photos was also mentioned as a motivation for learning the social media instrument.

"Facebook helps us carry out relations with people we meet on holiday, for example, on our last holiday in Greece we met people from the Peruvian Government and we keep in touch. My wife also uses it to keep in touch with her friends in Germany". (Man, 71, Bucharest)

In line with previous studies (Ivan \& Hebblethwaite, 2016) that suggested the use of photos to depict day to day life is a relevant media practice for older adults, participants stated that the possibility to send or post pictures online is a key motivating factor to use Facebook. This is also grounds to believe that the use of the Photo Voice approach is relevant for future studies.

"Photos: In our holidays we go to Greece for about two weeks, we have a place on the waterfront. We've been going there for years, the sunrise, the sunset, the moon, the entire atmosphere in this resort, when I come back I will post photos, this will be at the end of August" (Woman, 66, Braşov).

"I don't know if I will have a lot of time for Facebook, but I can first of all send photos and communicate more rapidly, the technology is very advanced, and it is, for us older people, a way of communicating more rapidly". (Woman, 62, Bucharest)

One other utility for Facebook is being able to participate in public debates and to express opinion more easily: "Since everyone, from the President [of Romania] to the last Romanian use Facebook, all the Television channels send you to Facebook, they say 'write to us on Facebook'. This is why I wanted to take this course, because I have so many things, certain moments when something annoys me or when I want to express my opinion, I don't know if it's enough or if it counts, but it matters to me because I can take it off my chest'. (Woman, 67, Bacău)

There is also evidence, in the participants' reflections, of the fact that online communication is perceived as an endeavor that could increase a sense of social connectedness and can act as a coping mechanism against loneliness: "When death is looking for you at home and you are attending workshops... I knew a little bit because my son bought me a tablet after my husband died and I had a difficult time, and he said I can try to communicate online". (Woman, 84, Braşov)

\section{Using Social Media to "Keep Up"}

When discussing their motivation to learn how to use Facebook, participants often compared their situation to that of younger people, children, or grandchildren; learning how to 
use Facebook was perceived as a way to "keep up" with younger generations and with general trends.

\begin{abstract}
"So, what can I tell you, I like to communicate, and I want more and more but there was nobody to initiate me, even though all of my family works on computers and use Facebook, but nobody was patient to teach grandma? Yes, and so, I said that I have to, even though this technology came a bit too late for us but we are trying, I think we are succeeding". (Woman, 68, Braşov)

“My first reaction came about one year after I retired: 'Why do I need a smartphone?!'... But after a year and a half I was looking around me and everyone was always tapping on their phones, and I wasn't. When I started, I realized how much I had missed, a year and a half, but I haven't given up". (Man, 70, Braşov).
\end{abstract}

\title{
Potential for Long-term Empowerment When Using Social Media
}

Regarding RQ3, our findings suggest that, consistent with the observations made by Fudge, Wolfe, \& McKevitt (2007) the PAR design was effective not only in increasing participants' knowledge, but also their confidence in using the proposed digital technology. Participants indicated increased familiarity with the social media site and, when reflecting on their intent to use Facebook after the conclusion of the study, participants perceived it very likely to continue engaging with said digital platform.

"I would like to use it every day, and I think if I want it so much, I deserve to spend one hour per day on Facebook" (Woman, 67, Braşov).

“I hope I don’t become addicted!" (Woman, 69, Braşov)

"I will be able to post photos and videos, which I did not know how to post before I came here". (Woman, 72, Bacău)

"I now know, approximately, how to use Facebook. And I can also use e-mail, post photos, and this is enough for the moment." (Woman, 85, Bucharest)

"I will probably use Facebook because I am often out of the country. I do have Skype and I have people's emails, but anyway not everyone uses e-mail and a lot of people only have Facebook. I used to get annoyed 'you only have Facebook, and I don't have Facebook!'” (Woman, 68, Brașov)

For future studies, conducting PAR in a longitudinal multi-case design would allow for follow-up interventions and interactions, in order to analyse the potential medium and long-term effects of the collaborative study design in empowering older adults to use digital media.

\section{Conclusions}

Participatory Action Research is a methodology used to better understand communities and their problems, to collaboratively collect and reflect on research data, in an endeavor that blurs the lines and the power dynamics between researchers and the researched. Individual PAR designs can differ, but a common thread is an intention to empower members of a community to reflect on their situations and to consider courses of action for social change, narrowing the gap between research and intervention.

We revealed particular features of Participatory Action Research in the area of technology creation and appropriation. We discussed it first as a model of involving users in co-creation 
of product design, and then as a way to involve the end-users of different type of technologies in research and development areas. Also, we analyzed types of Participatory Action Research: Ethnographic approach and Photo Voice. Here we argue that both techniques could be successfully used to research on media practices at older individuals. Although studies which implement PAR to study ICT use and appropriation are scarce, we provided at least two arguments that such methodological option could be valuable when researching older people.

First, older people might approach different communication and information technology for different reasons compared to younger ones. Second, findings showed that older adults are interested in using photos in the process of technology appropriation; therefore Photo Voice could be implemented as a successful technique. We discussed the benefits and possible long-term impact of using PAR with old participants, particularly regarding familiarity with different applications, and self-confidence. In the end, we presented a participatory research design for a study on the way older people are using Facebook and the way participants perceived the experience of learning from younger individuals.

\section{References}

Burrows, A., Mitchell, v. \& Nicolle, C.A. (2016). Let's spend some time together: exploring the out-of-box experience of technology for older adults. International Journal of Mobile Human Computer Interaction, 8 (2), pp.69-82. DOI: https://doi.org/10.4018/IJMHCI.2016040104.

Carmona, M. (2010). Public places, urban spaces: the dimensions of urban design. London: Routledge.

Chakraborty, R., Vishik, C., Rao H.R., Privacy preserving actions of older adults on social media: Exploring the behavior of opting out of information sharing. Decision Support Systems 55 (2013) 948-956; DOI: https://doi.org/10.1016/j.dss.2013.01.004.

Chevalier, J. M., \& Buckles, D. (2013). Participatory action research: Theory and methods for engaged inquiry. London: Routledge.

Demiris, G., Oliver, D. P., Dickey, G., Skubic, M., \& Rantz, M. (2008). Findings from a participatory evaluation of a smart home application for older adults. Technology and Health Care, 16(2), 111-118.

Ding, D., Cooper, R. A., \& Pearlman, J. (2007, July). Incorporating participatory action design into research and education. In International Conference on Electrical Engineering. ICEE. Coimbra, Portugal.

Fernández-Ardèvol, M., \& Ivan, L. (2015). Why Age Is Not that Important? An Ageing Perspective on Computer Anxiety. In Human Aspects of IT for the Aged Population. Design for Aging (pp. 189-200). Springer International Publishing. DOI: https://doi.org/10.1007/978-3-319-20892-3_19.

Fernández-Ardèvol, M., \& Ivan, L. (2013). Older People and Mobile Communication in Two European Contexts. Romanian Journal of Communication \& Public Relations, 15(3), 83-98. DOI: https://doi.org/ 10.21018/rjcpr.2013.3.196 .

Flicker, S., Maley, O., Ridgley, A., Biscope, S., Lombardo, C., \& Skinner, H. A. (2008). e-PAR: Using technology and participatory action research to engage youth in health promotion. Action Research, 6(3), 285-303. DOI: https://doi.org/10.1177/1476750307083711.

Fudge, N., Wolfe, C. D. A., \& McKevitt, C. (2007). Involving older people in health research. Age and Ageing, 36(5), 492-500. DOI: https://doi.org/10.1093/ageing/afm029.

Genat, B. (2009). Building emergent situated knowledges in participatory action research. Action Research, 7(1), 101-115. DOI: https://doi.org/10.1177/1476750308099600.

Glaser, B. G. (1998) Doing Grounded Theory: Issues and Discussions. Mill Valley, CA.: Sociology Press.

Hergenrather, K. C., Rhodes, S. D., Cowan, C. A., Bardhoshi, G., \& Pula, S. (2009). Photovoice as communit y-based participatory research: A qualitative review. American Journal of health behavior, 33(6), 686-698.

Hickey, S. \& Mohan, G. (Eds) (2004). Participation: From Tyranny to Transformation? Exploring New Approaches to Participation in Development. London: Zed Books. 
Hitchen, S., Williamson, G. R., \& Watkins, M. (2015). Personal budgets for all? Implementing self-directed support in mental health services. Action Research, 1476750314568207. DOI: https://doi.org/10.1177/ 1476750314568207.

Givskov C., Deuze M, Researching new media and social diversity in later life. (2018). New media \& society, 20 (1): 399-412. DOI: https://doi.org/10.1177/1461444816663949.

Ivan, L., \& Hebblethwaite, S. (2016). Grannies on the net: Grandmothers' experiences of Facebook in family communication. Romanian Journal of Communication and Public Relations, 18(1), 11-25. DOI: https://doi.org/10.21018/rjepr.2016.1.199.

Ihm, J. \& Hsieh, P.Y. (2015) The implications of information and communication technology use for the social well-being of older adults. Information, Communication \& Society, 18 (10), 1123-1138. DOI: https://doi.org/10.1080/1369118X.2015.1019912.

Kalmus, V., Masso, A. and Lauristin, M. (2013). Preferences in media use and perception of inter-generational differences among age groups in Estonia: A cultural approach to media generations', Northern Lights, 11, 15-34. DOI: https://doi.org/10.1386/nl.11.15_1.

Kindon, S., Pain, R., \& Kesby, M. (Eds.). (2007). Participatory action research approaches and methods: Connecting people, participation and place. Routledge.

Muller, M. J. (2003). Participatory design: The third space in HCI. In J. Jacko \& A. Sears (Eds.), The Human-Computer Interaction Handbook (pp.464-481).Mahwah, NJ: Lawrence Erlbaum.

Napoli, A. (2014). Social media use and generational identity: Issues and consequences on peer-to-peer and cross-generational relationships - an empirical study. Participations. Journal of Audience \& Reception Studies, 11, 2, 183-206.

Piercy, F. P., Franz, N., Donaldson, J. L., \& Richard, R. F. (2011). Consistency and change in participatory action research: Reflections on a focus group study about how farmers learn. The Qualitative Report, 16(3), 820-829.

Randall. J. (2012). What is distinctive about working with older people using creative technology? - Digital Arts and Older People. The Baring Foundation - roundtable. September 2012. https://baring foundation.org.uk/resource/digital-arts-and-older-people-what-is-distinctive-about-working-with-older-people-us ing-creative-technology/ accessed on 02.01.2018.

Seale, J., McCreadie, C., Turner-Smith, A., \& Tinker, A. (2002). Older people as partners in assistive technology research: the use of focus groups in the design process. Technology and Disability, 14(1), 21-29.

Slegers, K., Duysburgh, P., van Rijn, H., \& Hendriks, N. (2012, August). Participatory design for users with impairments affecting cognitive functions and communication skills. In Proceedings of the 12th Participatory Design Conference: Exploratory Papers, Workshop Descriptions, Industry Cases-Volume 2 (pp. 141-142). ACM. DOI: https://doi.org/10.1145/2348144.2348190.

Rodriguez, C. (2001). Fissures in the Mediascape: An International Study of Citizens' Media. Cresskill, NJ: Hampton Press.

Spinuzzi, C. (2005). The methodology of participatory design. Technical communication, 52(2), 163-174.

Tacchi, J., Foth, M., \& Hearn, G. (2009). Action research practices and media for development. International Journal of Education and Development using Information and Communication Technology, 5(2), 32-48.

Tamme, V., Siibak, A. (2012). Enhancing Family Cohesion through Web-Based Communication: Analysis of Online Communication Practices in Estonian Families. Observatorio. Journal, Special issue "Networked belonging and networks of belonging", 1-28. DOI: http://dx.doi.org/10.15847/obsOBS000581.

Taylor, R. R., Braveman, B., \& Hammel, J. (2004). Developing and evaluating community-based services through participatory action research: two case examples. American Journal of Occupational Therapy, 58(1), 73-82.

Wang, C. C. (1999). Photovoice: A participatory action research strategy applied to women's health. Journal of Women's Health, 8(2), 185-192.

Wu, M., Richards, B., \& Baecker, R. (2004, July). Participatory design with individuals who have amnesia. In Proceedings of the eighth conference on Participatory design: Artful integration: interweaving media, materials and practices-Volume 1 (pp. 214-223). ACM. DOI: http://dx.doi.org/10.1145/ 1011870.1011895. 